\title{
The Prevalence of Cryptosporidium in rivers water in Basra Province
}

\author{
Mahmoud S. Thamer ${ }^{1}$, Maitham H. Shanoot ${ }^{2}$, Wathiq A. Al-Rmadhan ${ }^{3}$ \\ \{mahmood.Thamir@stu.edu.iq ${ }^{1}$, maitham.altai@stu.edu.iq ${ }^{2}$,wathiq.alrmadhan@stu.edu.iq $\left.q^{3}\right\}$ \\ Technical Institute, Environmental Pollution Research, Southern Technical University, Basra, \\ $\operatorname{Iraq}^{1}{ }^{\prime}{ }^{\prime} 3$
}

\begin{abstract}
The study included testing 300 liters of water from five rivers in Basra from December 2012 to November 2013 for detection of Cryptosporidium spp oocysts in rivers water (Al-Ashar, Al-Ribat, Al-khandiq, Alkhora and Shatt Al-Arab), each sample was concentrated and Stained with A modified Zheil-Nielson. The results revealed that the prevalence of Cryptosporidium oocysts was (13.7\%). The percentages of prevalence with Cryptosporidium were in high rate in Al-khandiq river $(6.41 \%)$ while the low rates were in Al-Ribat river $(2.42 \%)$. This first study shows the occurrence of Cryptosporidium oocysts in rivers in Basra Province.
\end{abstract}

Keywords: Cryptosporidium, Rivers Basra.

\section{Introduction}

Within the past decades, the epidemiology of protozoan waterborne diseases has changed. There has been an upsurge in the incidence of waterborne outbreaks, sometimes known as cholera outbreaks. This is not only to increased susceptibility to diseases but also to the emergence of newly recognized waterborne parasites [5, 9]. Outbreaks caused by drinking water were attributed to several factors; contamination of the water source by heavy rainfall, snow melts, or agricultural runoffs which wash parasites from land areas into surface water, and contamination of water wells and canals by soil or by dead animal's carcasses thrown into them [10]. Cryptosporidium sp. is a worldwide infection that is expected to be more prevalent in developing nations, particularly among youngsters [4]. Insects play a crucial role in Oocyst transmission through a variety of pathways, including direct contact with infected people or animals, consumption of contaminated food (foodborne transmission), and water (waterborne transmission) [2]. Exoskeletons and digestive tracts of house flies, cockroaches, beetles, and synanthropic flies can all spread oocysts [3]. Numerous studies show that polluted water is a significant risk factor for cryptosporidiosis. Cryptosporidiosis accounts for up to $15 \%$ of gastrointestinal illnesses among children in impoverished countries, with seroprevalence rates ranging from $25 \%$ to 35 percent [8]. The goal of this study was to find out how common Cryptosporidium spp. were in some river resources. 


\section{Materials and Methods}

\subsection{Samples Water for Test}

Water samples were taken in Basra province from December 2012 to November 2013. A total of 300 litters of water samples were collected from rivers (Al-Ashar, Al-Ribat, Al-khandiq, Alkhora, and Shatt Al-Arab) and placed in polyethylene containers, which were then delivered to the parasitological laboratory at the university of Basra's college of education. The water of the river was collected from the surface twenty monthly samples were taken from each type of river.

\subsection{Oocyst Detection}

To detect Cryptosporidium oocysts, a modified Zehil Neelson stain method was used. Water samples were centrifuged, and a drop was taken from each deposit with a Pasture pipette and smeared on a glass slide. The smears were then fixed transiently over a flame and stained with a strong carbol fuchsin solution for 5 minutes. The slide was heated until steam formed, but not to the point of boiling, and an extra stain was applied if the slide became dry. The smear was stained, then washed under running tap water for 1-2 minutes before being decolorized in 5\% sulphuric acid for 30 seconds. The smears were rinsed in tap water for 1-2 minutes before being counterstained for 1 minute with 3 percent methylene blue stain. Finally, the smears were rinsed in tap water, air-dried, and inspected microscopically for Cryptosporidium oocysts under oil immersion (100). The following formula was used to compute the percentage of contaminated samples:

Percentage of infected samples $=\frac{\text { Number of infected samples }}{\text { Total number of samples }} \times 100$

\subsection{Statistical Analysis}

After data cleaning, the data was transferred to a Microsoft Excel Spreadsheet for statistical analysis, and then into the SPSS (Statistical Package for the Social Sciences version 15.) package software application. For all variables, descriptive statistics (\%) were performed, as well as analytical statistics to determine the relationships between the variables. Chi-square statistical tests were used to determine the relationship between variables.

\section{Results}

As shown in Figures 1 and 2, and Table 1, Cryptosporidium oocysts were identified in 37 of 300 litters of water samples, for a total prevalence of 31.25 percent. 


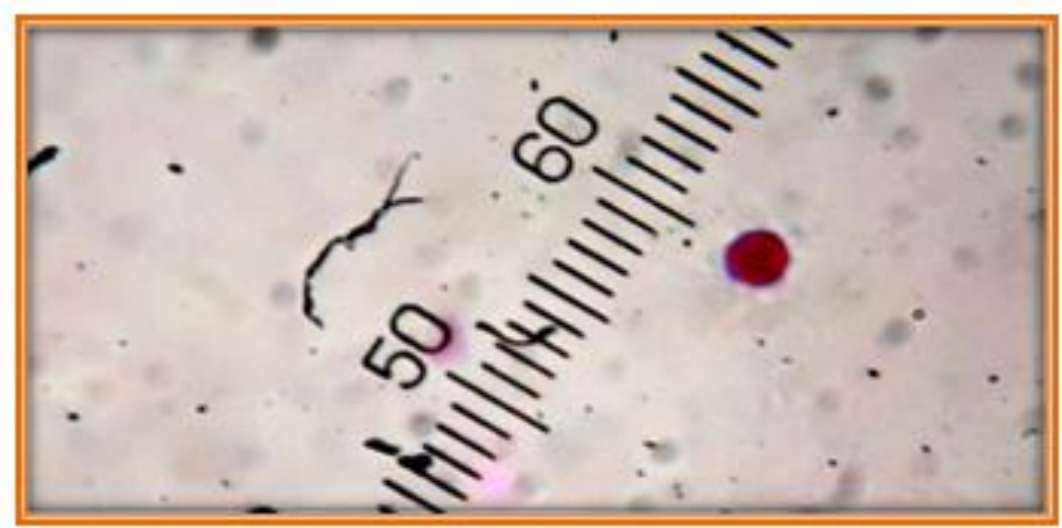

Fig 1: Zeihl Neelsen modified staining of cryptosporidium oocysts at 100X.

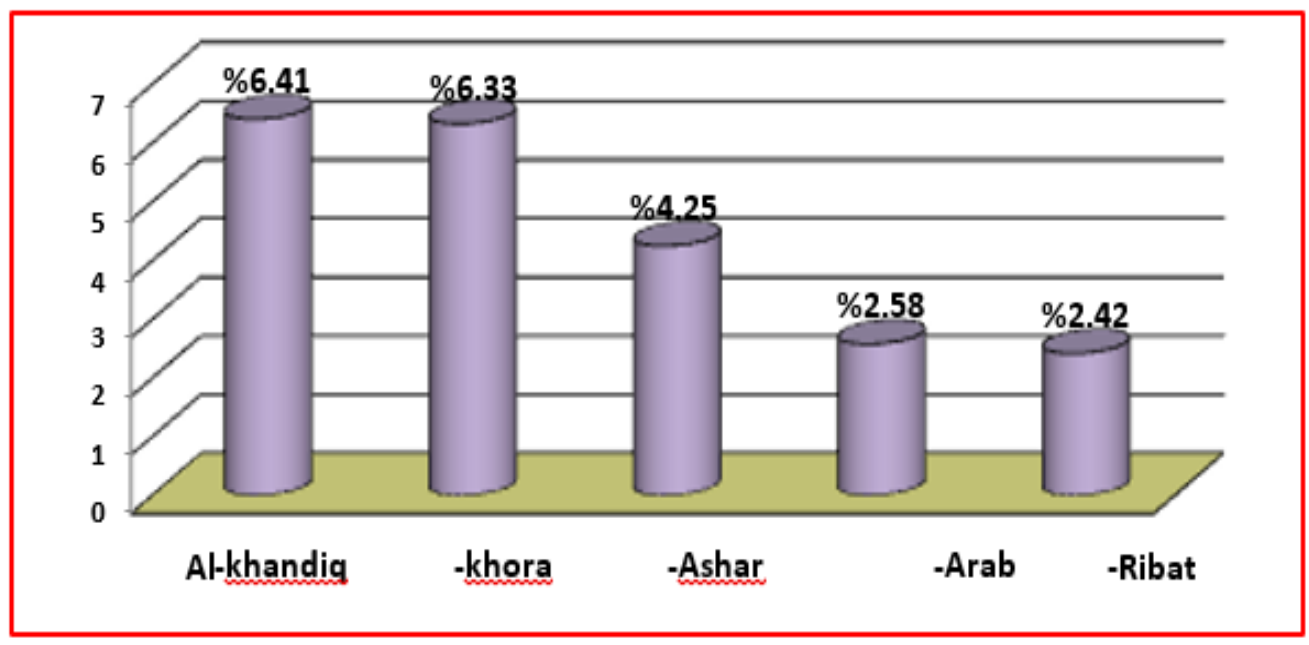

Fig 2: Prevalence of Cryptosporidium oocysts in some rivers water.

Table 1: Cryptosporidium's Overall Prevalence.

\begin{tabular}{|l|l|l|l|l|}
\hline Name of Parasite & $\begin{array}{l}\text { No. of } \\
\text { Examined } \\
\text { samples / L }\end{array}$ & $\begin{array}{l}\text { No. of } \\
\text { infected } \\
\text { samples }\end{array}$ & $\begin{array}{l}\text { Average } \\
\text { oocyst /L }\end{array}$ & $\begin{array}{l}\text { Percentage of } \\
\text { infected } \\
\text { samples }\end{array}$ \\
\hline Cryptosporidium & 300 & 37 & 4.4 & $13.7 \%$ \\
\hline
\end{tabular}




\section{Discussion}

Cryptosporidiosis is one of the most common diarrheal disorders caused by protozoan parasites, and it is a serious public health concern globally [7], however epidemiological research for this parasite are few in Iraq [1]. The importance of water and food in the spread of this disease is now widely acknowledged; water is likely to be the most common pathway for large-scale outbreaks of the disease, as a result of contamination of either raw or processed water [6].

In this study, we found that from (300) $\mathrm{L}$ water samples examined (37) L were positive for oocyst of Cryptosporidium with the rate of (13.7\%), this result agrees with [5] who found the parasite in water samples collected from (Al-Ashar, Al-Ribat, Al-khandiq, Al-khora, and Shatt AlArab) in Basra province which is in access of animals and contamination those rivers with faecal materials which come from sewage water, our result disagrees with (Ali, 1998) he did not find the oocyst of the parasite in lake water in Basra province this might be due to the different source of study be carried out on lake water from housing and animal treading.

The present study revealed that no significant difference between the five rivers although the high rate was recorded in Al-khandiq river $(6.41 \%)$, while the low rate was recorded in Al-Ribat river $(2.42 \%)$. 


\section{References}

1. Al-Baytee, A. J.; Jawad, S. Q. and Mehdi, H. S. (2012). Prevalence of Cryptosporidium oocysts in different types of water in Al-Mansoria diala Province. J. Al-Nahrain Univ., 1(15): 103-107.

2. Ali, N. H. (1998). Prevalence of Cryptosporidiosis with zoonotic aspect., M.Sc.

3. Thesis, Coll. Med. Univ. Basrah.

4. Al-Shamiri , A.H.; Al- Zubairy, A.H.; Al-Mamari, R. F.(2010). The Prevalence of Cryptosporidium spp. in Children, TaizDistrict, Yemen. Iranian, J .Parasitol: Vol. 5(2), PP. 26-32.

5. Collins, P.A; Wright, M.S. (1997). Emerging intestinal protozoa: A diagnostic dilemma. Clin Lab Sci, 10(5):273-8.

6. Hvnter, P. R. and Thompson, R.C. (2005). "The zoonotic transmission of Giardia and Cryptosporidium". Int. J. Parasitol.; 35: 1181-1190.

7. Johason, D. W; Pieniuazek, N.J.; Griffin, D.W.; Mispner, L. and Rose, J. B. (1995). "Development of a PCR protocol for sensitive detection of Cryptosporidium oocysts in water samples". App. Environ. Microbiol. 61; 3849-3855.

8. Juranek , D. D.( 2000). Cryptosporidiosis. In: Hunter's Trop. Med. and Emerging Infectious Disease. Strickland, G. Thimas (Editor) 8th ed. WB Saunders Company Ltd. London, P. $594-600$.

9. Leclerc, H.; Schwartzbrod, L.; Dei-Cas, E. (2002). Microbial agents associated with waterborne diseases. Crit. Rev. Microbiol.; 28(4):371-409.

10. Mac Kenzie, W.R.; Hoxie, N.J.; Proctor, M. E. (1994). A massive outbreak in Milwaukee of Cryptosporidium infection transmitted through the public water supply. Engl. J. Med.; 331(3): 161-7

11. Meinhart, P.L.; Casemore, D.P; Miller, K.B.(1996). Epidemiologic Aspects of human cryptosporidiosis and the role of waterborne transmission. Epid Rev.; 18(2):118-36. 